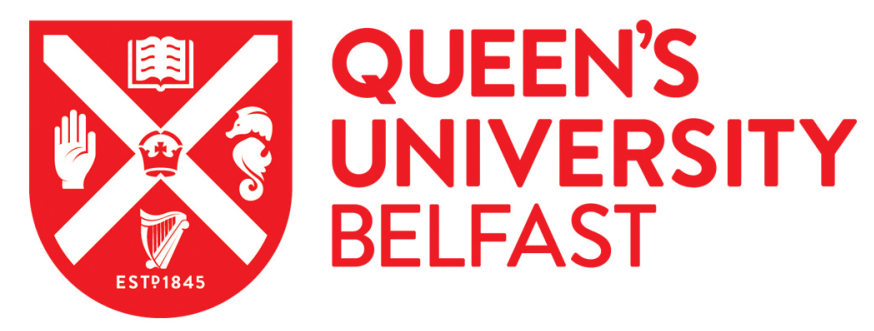

\title{
Slow saccades in bulbar-onset motor neurone disease
}

Donaghy, C. G., Pinnock, R. A., Abrahams, S., Cardwell, C., Hardiman, O., Patterson, V., McGivern, C., \& Gibson, J. M. (2010). Slow saccades in bulbar-onset motor neurone disease. Journal of Neurology, 257(7), 1134-1140. https://doi.org/10.1007/s00415-010-5478-7

Published in:

Journal of Neurology

Queen's University Belfast - Research Portal:

Link to publication record in Queen's University Belfast Research Portal

\section{General rights}

Copyright for the publications made accessible via the Queen's University Belfast Research Portal is retained by the author(s) and / or other copyright owners and it is a condition of accessing these publications that users recognise and abide by the legal requirements associated with these rights.

Take down policy

The Research Portal is Queen's institutional repository that provides access to Queen's research output. Every effort has been made to ensure that content in the Research Portal does not infringe any person's rights, or applicable UK laws. If you discover content in the Research Portal that you believe breaches copyright or violates any law, please contact openaccess@qub.ac.uk. 


\title{
Slow saccades in bulbar-onset motor neurone disease
}

\author{
Colette Donaghy - Ralph Pinnock - Sharon Abrahams \\ Chris Cardwell - Orla Hardiman - Victor Patterson . \\ R. Canice McGivern - J. Mark Gibson
}

Received: 18 August 2009/Revised: 3 November 2009/Acceptec: 15 January 2010/Published online: 10 February 2010

(C) Springer-Verlag 2010

\begin{abstract}
Historical studies of eye movements in motor neurone disease (MND) have been conflicting although current findings suggest that eye movement abnormalities relate to frontal lobe impairment. Numerous case reports, however, describe slow saccades and supranuclear gaze palsies in patients with MND often associated with bulbaronset disease. We performed a study of saccades and smooth pursuit in a large group of patients with MND to examine for any differences between bulbar-onset and spinal-onset patients. Forty-four patients (14 bulbar-onset and 30 spinal-onset patients) and 45 controls were recruited. Refiexive saccades, antisaccades and smooth pursuit were examined using infra-red oculography and all subjects then underwent neuropsychological evaluation. Refexive saccades were found to be slower in bulbar-onset compared to spinal-onset patients and controls $(p=0.03$, $p=0.05)$. Antisaccade latency $(p=0.01)$ and antisaccade
\end{abstract}

C. Donaghy ( $\bigotimes$ ) - V. Patterson - J. M. Gibson Department of Neurology, Royal Victoria Hospital. Belfast BT12 6BA, Northern Ireland, UK

e-mail: donaghyla@hotmail.com

R. Pinnock - R. C. McGivern

Northern Ireland Regional Medical Physics Agency, Royal Victoria Hospital, Belfast, Northern Ireland, UK

\section{S. Abrahams}

Department of Psychology, School of Philosophy, Psychology and Language Sciences, University of Edinburgh, Edinburgh, Scotland, UK

C. Cardwell

School of Medicine and Dentistry, Royal Victoria Hospital, Queens University of Belfast, Belfast, Nonhern Ireland, UK

O. Hardiman

Department of Neurology, Beaumont Hospital, Dublin, Ireland type 1 errors $(p=0.03, p=0.04)$ were increased in patients compared to controls. 'Proportion of time spent in smooth pursuit' and smooth pursuit 'velocity gain' were reduced in patients compared to controls ( $p=0.000$, $p=0.001$ ). Antisaccade errors and velocity gain correlated with neuropsychological measures sensitive to lesions of the frontal lobes. This is the first study to highlight the presence of slow saccades in bulbar-onset MND. These findings suggest that slow saccades may be due to increased brainstem pathology in bulbar-onset disease that involves burst cell neurons. Furthermore these observations highlight the potential for overlap between bulbar-onset MND and progressive supranuclear palsy (PSP) as both can have a bulbar palsy and slowed saccades.

Keyw'ords Motor neurone disease - Saccades Smooth pursuit

\section{Introduction}

The most recent studies of eye movements in MND suggest that the underlying aetiology is that of frontal lobe impairment. Shaunak et al. [42] found significantly elevated error rates and latency in antisaccade and remembered saccade paradigms, with relative preservation of reflexive saccades and a significantly increased frequency of small saccades intruding on fixation. Smooth pursuit was found to be normal. These findings were felt to suggest frontal lobe impairment as lesional studies of the frontal eye fields cause increased latency of antisaccades but not refiexive saccades [40]. Futhermore, increased antisaccadic errors have been associated with lesions of the prefrontal cortex [39]. Functional imaging studies in humans have further delineated the role of the cortical eye fields in 
saccade generation. A recent study found that the frontal eye fields (FEFs) were predominantly concemed with voluntary (endogenously generated) saccades while reflexive saccades (those made in response to an external stimulus) correlated with activation in the angular gyrus of the inferior parietal lobe [30] in the region of the PEF. Another study of eye movements in MND [12] found that one-third of 51 patients with MND displayed high distractibility (as evidenced by antisaccade errors) and that this correlated with some components of frontal lobe neuropsychological tests (STROOP and WCST). More recently the neuropsychological profile of apparently nondemented MND patients has been characterised as a subclinical frontal lobe dysfunction $[1,3,4,13-15,20,24,26]$. Recent work by the authors formally examined ocular fixation for the first time in MND and found that saccadic intrusion amplitude correlated with tests sensitive to lesions of the frontal lobe [11]. These findings point to frontal lobe impairment as the basis of eye movement abnormality in MND.

Numerous abnormalities, however, have been reported in the literature including slow saccades $[6,17,23,34,35]$, saccadic interruption of smooth pursuit $[23,36]$, gaze palsies $[36,41]$, horizontal gaze nystagmus [41], difficulties in maintaining fixation [37] and reduced smooth pursuit gain $[2,17,23,34]$. Many of these studies, however, were very small, lacked controls and pre-dated the El Escorial criteria (EEC) [8]. Several case reports, however, have described slow saccades and supranuclear gaze palsies in patients with MND often associated with cognitive impairment, advanced or bulbar-onset disease $[6,21,35$, 47]. Some of these had supportive neuropathological evidence of MND and one case report was able to show clinico-pathological correlation for slow vertical saccades by the finding of gliosis in the riMLF (rostral interstitial medial longitudinal fasciculus) which houses the burst cell neurons for vertical saccades [6]. It is likely therefore that if saccades were slow in MND it would be more obvious in bulbar-onset compared to spinal-onset disease. The authors performed a study of saccades and smooth pursuit in MND to examine for any differences between bulbar-onset and spinal-onset patients.

\section{Methods}

\section{Patients and controls}

The study was approved by the local ethics committee [Office for Research Ethics Committees in Northern Ireland (ORECNI)] and was therefore performed in accordance with the ethical standards laid down in the 1964 Declaration of Helsinki. Inclusion criteria included MND patients as defined by the original El Escorial criteria [8] excluding 'ALS/MND plus' cases or those with associated dementia as defined by the Neary Criteria [32]. Subjects were not on any medications known to affect eye movements nor had they any eye or brain conditions that would affect eye movements. All subjects had normal bedside ophthaimic examinations. Patients were alert and responsive during testing and displayed no clinical evidence of respiratory weakness or hypoxia and none required noninvasive ventilation support. Patients were recruited from the Northem and Republic of Ireland MND registers. Control subjects were recruited via patients' spouses or carers, hospital staff and healthy volunteers. All patients and controls gave informed consent before inclusion into the study.

\section{Demographic and clinical data}

Basic demographic and clinical data were collected including age and sex to allow for matching between patients and controls. Patients received the amyotrophic lateral sclerosis functional rating scale revised (ALSFRSr) [9] and a separate bulbar score was recorded from a component of the questionnaire. Disease duration was defined as the time from symptom onset to the date of inclusion in the study. Disease onset was recorded for each patient as spinal- or bulbar-onset. If a patient presented with both they were categorised as bulbaronset.

\section{Eye movement recording}

Eye movements were recorded using the infra-red scalar limbus system (Skalar Medical Iris Infra-red Light EyeTracker Model 6500) which records up to $\pm 15^{\circ}$ in the horizontal plane. The output of the system was filtered at $100 \mathrm{~Hz}(-3 \mathrm{~dB})$ and digitised to 12 bit resolution. Subjects were positioned in a hydraulic chair in the dark with their necks supported and their heads immobilised with head tongs. Measurements were recorded from one eye only. The height of the chair was adjusted to ensure that the subjects' eyes were level with the target stimulus. The target stimulus used for calibration and each task was a square of light subtending an angle of $0.25^{\circ}$ projected onto a black tangential screen $1.5 \mathrm{~m}$ away from the subject. VSG Eyetrace data acquisition software developed by CRS (Cambridge Research Systems) was employed to collect and process the data. Two of our authors, $R C M c G$ and $R P$, developed additional software to allow calculation of specific test parameters. Prior to the test, the equipment was calibrated to each subject. Data were stored in files in a password-protected computer. 
Reflexive saccade task

A-single-green-target moved between nine positions along a horizontal line between $\pm 15^{\circ}$. The target movements occurred at random time intervals to reduce anticipatory saccades. Subjects were requested to follow the green target. This task consisted of 100 target movements and lasted approximately $120 \mathrm{~s}$. For each saccade the following four measurements were recorded: latency, amplitude, peak velocity and duration. When peak velocity and duration are plotted against amplitude (called main sequence plots) the relationships can be characterised by mathematical equations. The peak velocity-amplitude main sequence plot can be explained by an exponential model and the duration-amplitude main sequence plot by a linear relationship where $A$ is saccadic amplitude, $K$ and $L$ are constants that describe the exponential slope of the data, $C$ is the intercept and $M$ represents the gradient of the line $[7],[16]$.

Peak velocity $=K\left(1-\mathrm{e}^{A / L}\right)$

Duration $=M A+C$

Although the duration-amplitude relationship is actually explained by a power relationship, it can be described by a more simple linear relationship for all except very small amplitude saccades. Mean latency, $K, L$ and $M$ values were used as outcome measures.

\section{Antisaccade task}

A central red stimulus was presented to the subjects before being replaced by a green stimulus at $\pm 3.838^{\circ}$, $7.673^{\circ}, 11.505^{\circ}$ or $15.329^{\circ}$, presented at random time intervals. Subjects this time were requested to fixate the central stimulus and when aware of the peripheral green stimulus, to look in the equal and opposite direction. This test consisted of 50 stimuli and lasted approximately $180 \mathrm{~s}$.

As in the reflexive saccade task, $K, L, M$ and latency values were measured as outcomes. These variables were based on correct or successful antisaccades. Typc 1 and type 2 absolute error counts were also measured as the total number of errors made throughout the recording. A type 1 error is where a subject looks incorrectly towards the stimulus and does not correct themselves while a type 2 error is where they do correct themselves.

\section{Smooth pursuit}

A white stimulus moved from across the screen from one side to the other before jumping back to its start point and starting again. This test was carried out at increasing speeds of $5,10,15,20$ and $25^{\circ} / \mathrm{s}$. The same sequence of tests was then repeated in the opposite direction. Ten tracings-were therefore recorded for each subject. Subjects were instructed to follow the light as closely as possible. Each of the pursuit tasks lasted for $20 \mathrm{~s}$. Outcome measures included velocity gain and proportion of time spent in smooth pursuit. Velocity gain is the ratio of stimulus to eye velocity during smooth pursuit where the eye velocity is calculated by taking the average of velocity data during a smooth pursuit period. The proportion of time spent in smooth pursuit is the total test time duning which smooth pursuit criteria (eye velocity within $10 \%$ s of target velocity) were met. The number of SIs that interrupted smooth pursuit were also measured including their geometric mean SI amplitude. Each record was examined separately to identify saccadic intrusions and prevent the inclusion of inappropriate eye movements such as blinks.

\section{Neuropsychological tests}

A brief neuropsychological evaluation was undertaken to test a range of cognitive functions. These included NART [33] and the Graded Naming Test (GNT) [28] to allow accommodation for intelligence and language, STROOP [46] and the verbal fiuency index (VFI) [5] to assess frontal lobe function, VOSP [48] to assess occipito-parietal function and the hospital anxiety and depression scale [49]. The VFI employed letter fluency using ' $s$ ' and ' $c$ ' letters. Further details of their use can be found in a previous publication [11].

\section{Statistical analyses}

Independent $t$ tests and one-way analysis of variance were used to compare means between groups for the eye movement variables and clinical and neuropsychological test variables. Some data sets required log transformation to allow parametric testing because of skewed distributions. For non-normally distributed data, the MannWhitney $U$ and Kruskal-Wallis $H$ tests were used. Multiple linear regression was used to compare means between groups whilst adjusting for covariates. Finally, correlation analyses were performed between any significant eye movement variable and neuropsychological tests and clinical measures of disease. For data not normally distributed, the Spearman's rank correlation coefficient was used instead of the Pearson's coefficient. To examine for an association between two continuous variables while adjusting for covariates, multiple linear regression was employed. 
Results

Demographic-and clinical-characteristics

Forty-four patients (15 females, 29 males) and forty-five controls ( 29 females, 16 males) were recruited. The groups were age-matched with a mean age of 60 years for both groups. There were 30 spinal-onset and 14 bulbar-onset cases. Mean and median disease duration was 52 and 39 months, respectively. The mean ALSFRSr score for patients was 35 (range 18-47).

\section{Saccades}

The results for saccades are displayed in Table 1. Reflexive saccades were normal in patients compared to controls, however, when a sub-group analysis was performed comparing spinal- and bulbar-onset cases with controls a statistically significant difference was found for ' $k$ ' $(p=0.03)$. ' $K$ ' represents the gradient of the velocityamplitude plot and is equivalent to saccade speed. Post hoc tests revealed that $K$ was reduced in bulbar-onset compared to spinal-onset patients (Bonferroni adjusted $p=0.03$, $F=3.8, d f=2$ ) and bulbar-onset compared to controls (Bonferroni adjusted $p=0.05, F=3.8, d f=2$ ).

Antisaccade latency was found to be increased in MND patients compared to controls but sub-group analysis failed to find any statistically significant differences between bulbar- and spinal-onset patients. A significant difference was observed between the groups for type 1 errors. Significant differences were noted between bulbar-onset and

Table 1 Saccades data for MND and control groups

\begin{tabular}{lcccl}
\hline & Bulbar-onset & Spinal-onset & $\begin{array}{l}\text { Control } \\
\text { group }\end{array}$ & $\begin{array}{l}\text { ANOVA } \\
p\end{array}$ \\
\hline $\begin{array}{l}\text { Reflexive saccades } \\
\text { Latency }\end{array}$ & $253.5(22.4)$ & $240.5(22.1)$ & $237.1(29.1)$ & 0.1 \\
(ms) & & & & \\
$K$ & $462.5(70)$ & $538.2(99.8)$ & $528.8(86.1)$ & 0.03 \\
$L$ & $6.7(2.0)$ & $7.6(1.5)$ & $7.9(1.7)$ & 0.08 \\
$M$ & $2.8(0.6)$ & $2.5(0.5)$ & $2.5(0.5)$ & 0.07 \\
Antisaccades & & & & \\
Latency & $495.9(133.5)$ & $441.9(83)$ & $406.2(90.8)$ & 0.01 \\
(ms) & & & & \\
$K$ & $319.1(171.3)$ & $382.5(135.1)$ & $381.6(127.7)$ & 0.5 \\
$L$ & $4.5(3.5)$ & $5.6(2.9)$ & $5.8(3.9)$ & 0.7 \\
$M$ & $8.1(7.0)$ & $5.1(2.9)$ & $1.4(0.5)$ & 0.1 \\
Type 1 & $2.9(3.4)$ & $1.1(1.3)$ & $1.1(2.6)$ & $0.002^{*}$ \\
Type 2 & $6.0(6.1)$ & $6.8(4.6)$ & $5.2(3.5)$ & 0.2 \\
\hline
\end{tabular}

Mean and standard deviations presented

* Non-parametric analysis using the Kruskall-Wallis test spinal-onset patients $(p=0.008)$ and bulbar-onset patients and controls $(p=0.002)$.

Smooth pursuit

'Velocity gain' and 'proportion of time spent in smooth pursuit' decrease with increasing speed. This decline was found to be more rapid in MND patients compared to controls (see Figs. 1, 2). The difference between patients and controls was examined by way of the gradient produced from data as displayed in Figs. 1 and 2. Mean 'velocity gain' reduced by 0.3 from 5 to $25 \%$ s in MND patients compared to 0.1 in controls $(p=0.001)$. Mean 'proportion of time spent in smooth pursuit' was reduced by $60 \%$ from 5 to $25 \%$ in MND patients compared to $40 \%$ in controls $(p=0.000)$. Velocity gain and proportion fell more sharply in bulbar-onset patients compared to spinalonset patients and controls but sub-group analyses did not reach statistical significance. The frequency of SIs that interrupted smooth pursuit was not found to be greater in MND patients compared to controls $(p=0.1)$. The amplitude of SIs during smooth pursuit did not differ between the groups $(p=0.1)$.

\section{Correlations}

No comelations were observed between saccade speed in bulbar-onset patients and any clinical or neuropsychological

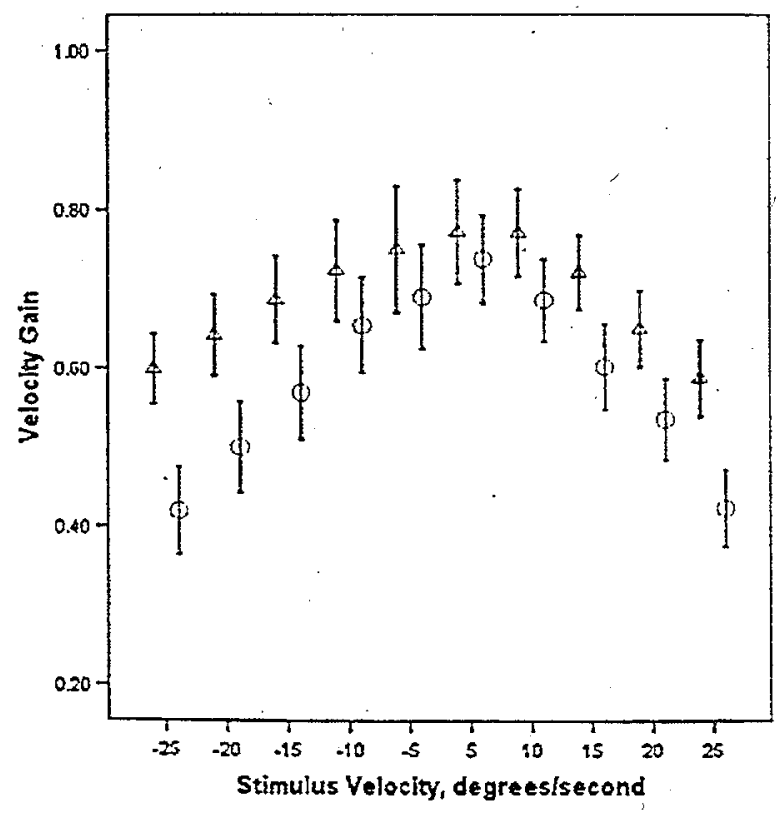

Fig. 1 Error graph demonstrating change in Smooth Pursuit 'velocity gain' dependent on stimulus velocity for MND patients and controls (Triangles represent controls and circles represent MND patients) 


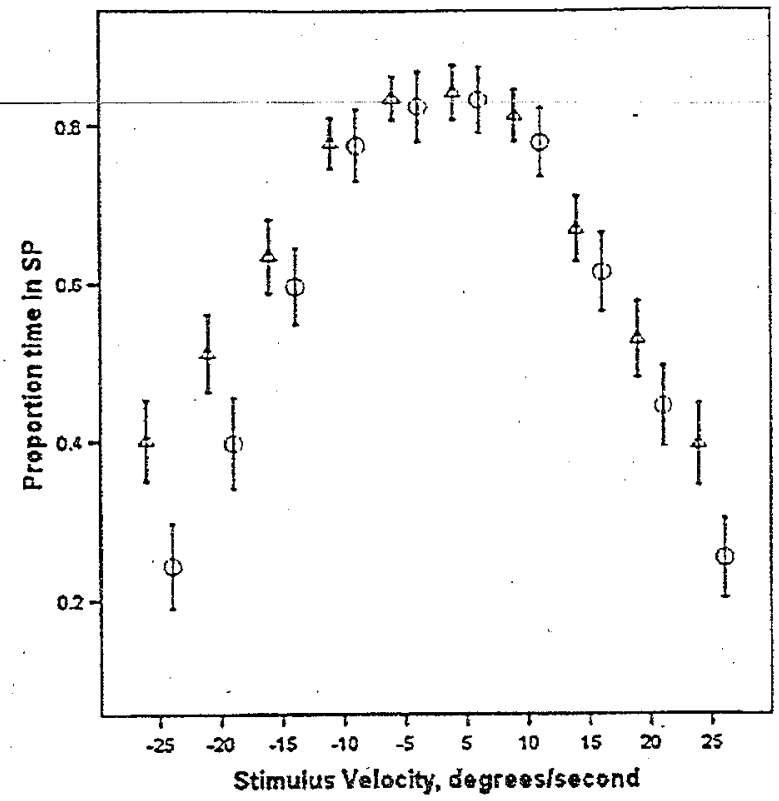

Fig. 2 Error graph demonstrating change in "proportion of time spent in smooth pursuit (SP)' dependent on stimulus velocity for MND patients and controls. (Triangles represent controls and circles represent $\mathrm{MND}$ patients)

measure. A significant correlation, however, was observed between type 1 errors and the STROOP test $(p=0.03)$. Errors increased with poorer scores on the STROOP test. Type 1 errors significantly correlated with the ALS-FRS $(p=0.000)$ and its bulbar component $(p=0.002)$ indicating that more severely disabled patients and patients with more severe bulbar disease had increased antisaccadic errors. A significant correlation was found between STROOP and the gradient of 'proportion of time spent in smooth pursuit' $(p=0.02)$. The relationship between the gradient of 'velocity gain' and the ALSFRSr bulbar component approached significance $(p=0.06)$.

\section{Discussion}

\section{Saccades}

While no difference was found between MND patients and controls for reflexive saccades, sub-group analysis found that reflexive saccades were slower in bulbar-onset patients. Shaunak et al. had found reflexive saccades to be nomal, however, earlier reports in the literature had found slowed saccades $[23,34]$. No study to date has looked specifically at saccades in bulbar-onset patients. Bulbar- onset patients are likely to have more extensive brainstem pathology compared to spinal-onset patients and are therefore more likely to have damage to the pre-motor burst cell and omnipause neurons of the midbrain and pons. Lesions in these areas are known to cause. slow saccades [22]. These findings might also heIp to explain case reports in the literature that describe slow saccades and supranuclear gaze palsies in patients with MND $[6,21,35,47]$. Where the diagnosis of MND relies heavily on clinical examination it is important to be aware of the spectrum of abnormalities that are consistent with the diagnosis. Eye movement recordings are performed in the clinical setting most commonly to look for slow saccades in parkinsonian patients, whom the physicians feel may be developing features of PSP. In this context therefore, the results in this study highlight the potential for confusion if presented with a patient with a pseudo-bulbar syndrome and slow saccades, as the diagnosis may be consistent with either MND or atypical PSP.

Increased antisaccadic latency and type 1 enrors were observed in MND patients compared to controls. These results are similar to those reported by Shaunak et al. [42]. While lesions of the FEFs cause patients to have increased latency of correct antisaccades with a normal percentage of errors $[38,40]$, studies have shown that lesions involving the DLPFC cause patients to have significantly more difficulty suppressing unwanted saccades than controls $[18,27,38,39]$. The suppression of unwanted saccades is equivalent to increased antisaccadic errors. These findings were supported by a functional MRI study by Muri et al. [31] who found significantly increased activation in the DLPFC of ten healthy subjects performing an antisaccade compared to a saccade task. The DLPFC connects to the superior colliculus either directly or indirectly via the basal ganglia/thalamus indicating that increased antisaccade errors could be caused by a defect anywhere along this pathway [22]. However, a study examining patients with discrete lesions along this pathway found that those patients with lesions of the thalamus or basal ganglia exhibited nomal antisaccadic errors, supporting the hypothesis that antisaccadic errors relate to the direct DLPFC-superior colliculus pathway [10]. The finding of increased antisaccadic latency and type 1 errors in MND patients in this study therefore implicates the involvement of the FEF and DLPFC and is supported by the correlation found between type 1 errors and the STROOP test. Furthemore, type 1 errors correlated with the ALS-FRS and its bulbar component indicating that patients with more bulbar dysfunction have higher levels of distractibility. This was also found by Evdokimidis et al. [12] who found a correlation between distractibility and dysarthria on the Appel score. 
Smooth pursuit

The decline in velocity gain and the proportion of time spent in smooth pursuit with increasing speeds occurred at a faster rate in MND patients compared to controls. Shaunak et al. [42] in 1995 found smooth pursuit to be normal while four eariier studies $[23,25,29,34]$ smooth pursuit gain was found to be reduced. In another study abnormal smooth pursuit was observed due to the breakdown of the smooth tracking by saccadic interruptions or intrusions [19]. Many cortical regions are involved in the control of smooth pursuit $[22,45]$ and therefore abnormalities found might be felt to be non-discriminatory, however, smooth pursuit representation in the FEF is felt to be involved in setting the gain of pursuit eye movements $[43,44]$. This would allow an impaiment of frontal lobe functions explain the abnormalities of smooth pursuit that have been demonstrated.

\section{Summary}

Reflexive saccades appear to be slow in bulbar-onset MND compared to spinal-onset patients and controls. This is likely to be as a direct result of brainstem involvement, in particular the burst cell neurons of the midbrain and pons. Caution must be exercised, however, in distinguishing bulbar-onset MND from PSP when a patient a pseudobulbar palsy presents with slow saccades. It would be of use to know, whether saccades in bulbar-onset MND become progressively slowed over time as they could then be used as biomarker of disease.

Acknowledgments We would like to thank all the patients and volunteers who gave of their time to participate in this study. We would also like to thank Mrs. Carol Montgomery and the Neurophysiology department in the Royal Victoria Hospital, Belfast, for

\section{References}

1. Abe K, Fujimura H, Toyooka K, Sakoda S, Yorifuji S, Yanagihara $T(1997)$ Cognitive function in amyotrophic lateral sclerosis. J Neurol Sci 148:95-100

2. Abel LA, Williams IM, Gibson KL, Levi L (1995) Effects of stimulus velocity and acceleration on smooth pursuit in motor neuron disease. I Neurol 242:419-424

3. Abrahams $S$, Goldstein LH, Al-Chalabi A, Pickering A, Morris RG, Passingham RE, Brooks DJ, Leigh PN (1997) Relation between cognitive dysfunction and pseudobulbar palsy in 62:464-472 lateral sclerosis. J Neurol Neurosurg Psychiatry

4. Abrahams $S$,

CD, Leigh PN (1906) LH, Kew JJ, Brooks DJ, Lloyd CM, Frith lateral sclerosis. A PET study.

5. Abrahams S, Leigh PN study. Brain I $19(\mathrm{Pt} 6): 2105-2120$

Goldstein LH (2000) Verbal amyotrophic lateral sclerosis (ALS). Neuropsychologia 38:734-
747

6. Averbuch-Heller L, Helmchen C, Hom AK, Leigh RJ, ButtnerEnnerver JA (1998) Slow vertical saccades in motor neuron disease: correlation of structure and function. Ann Neurol 44:641-648

7. Baloh RW, Konrad HR, Sills AW, Honrubia V (1975) The saccade velocity test. Neurology 25:1071-1076

8. Brooks BR (1994) El Escorial World Federation of Neurology criteria for the diagnosis of amyotrophic lateral sclerosis. Subcommittee on Motor Neuron Diseases/Amyotrophic Lateral Scierosis of the World Federation of Neurology Research Group on Neuromuscular Diseases and the El Escorial "Clinical limits of amyotrophic lateral sclerosis" workshop contributors. I Neuro! Sci 124(Suppi):96-107

9. Cedarbaum JM, Stambler N, Malta E, Fuller C, Hilt D, Thurmond B, Nakanishi A (1999) The ALSFRS-R: a revised ALS functional rating scale that incorporates assessments of respiratory function. BDNF ALS Study Group (Phase III). J Neurol Sci 169:13-21

10. Condy C, Rivaud-Pechoux S, Ostendorf F, Ploner CJ, Gaymard B (2004) Neural substrate of antisaccades. Role of subcorical structures. Neurology 63:1571-1578

11. Donaghy C, Pinnock R, Abrahams S, Cardwell C, Hardiman O, Patterson V, McGivem RC, Gibson JM (2009) Ocular fixation instabilities in motor neurone disease: a marker of frontal lobe
dysfunction? I Neurol $256: 420-426$

12. Evdokimidis I, Constantinidis TS, Gourzeiidis P, Smymis N, Zalonis I, Zis PV, Andreadou E, Papageorgiou C (2002) Frontal lobe dysfunction in anyotrophic lateral scierosis. J Neurol Sci
195:25-33

13. Frank B, Haas J, Heinze HJ, Stark E, Munte TF (1997) Relation of neuropsychological and magnetic resonance findings in amyotrophic lateral sclerosis: evidence for subgroups. Clin Neurol Neurosurg 99:79-86

14. Gallassi R, Montagna P, Ciardulli C, Lorusso S, Mussuto V, Stracciari A (1985) Cognitive impairment in motor neuron disease. Acta Neurol Scand 71:480-484

15. Gallassi R, Montagna P, Morreale A, Lorusso S, Tinuper $P$, Daidone R, Lugaresi E (1989) Neuropsychological, electroencephalogram and brain computed tomography findings in motor neuron disease. Eur Neuro! 29:115-120

16. Garbutt S, Harwood MR, Kumar AN, Han YH, Leigh RJ (2003) Evaluating small eye movements in patients with saccadic palsies. Ann N Y Acad Sci 1004:337-346

17. Gizzi M, DiRocco A, Sivak M, Cohen B (1992) Ocular motor function in motor neuron disease. Neurology 42:1037-1046

18. Guitton D, Buchtel HA, Douglas RM (1985) Frontal lobe lesions in man cause difficulties in suppressing reflexive glances and in generating goal-directed saccades. Exp Brain Res 58:455-472

19. Jacobs L, Bozian D, Heffner RR $J_{r}$, Barron SA (1981) An eye movement disorder in amyotrophic lateral sclerosis. Neurology
$31: 1282-1287$

20. Kew JJ, Goldstein LH, Leigh PN, Abrahams S, Cosgrave N, Passingham RE, Frackowiak RS, Brooks DJ (1993) The relationship between abnormalities of cognitive function and cerebral activation in amyotrophic lateral sclerosis. A neuropsychological and pasitron cmission tomography study. Brain $116\left(\mathrm{Pt}_{\mathrm{t}} 6\right): 1399$
1423

21. Kobayashi M, Ikeda K, Kinoshita M, Iwasaki Y (1999) Amyotrophic lateral sclerosis with supranuclear ophthalmoplegia and
rigidity. Neurol Res $21: 661-664$

22. Leigh RJ, Zee DS (2006) The neurology of eye movements.
Oxford University Press, New York Oxford University Press, New York

3. Leveille A, Kicman J, Goodwin JA, Antel I (1982) Eye movements in amyotrophic lateral sclerosis. Arch Neurol 39:684-686 
24. Ludolph AL, Langen KJ, Regard $M$, Herzog $H$, Kemper $B$, Kuwert T, Bottger IG, Feinendegen L (1992) Frontal lobe function in amyotrophic lateral sclerosis: a neuropsychologic and positron emission tomography study. Acta Neurol Scand 85:8189

25. Marti-Fabregas J, Roig C (1993) Oculomotor abnormalities in motor neuron disease. J Neurol 240:475-478

26. Massman PJ, Sims J, Cooke N, Haverkamp IJ, Appel V, Appel SH (1996) Prevalence and correlates of neuropsychological deficits in amyotrophic lateral sclerosis. I Neurol Neurosurg Psychiatry $61: 450-455$

27. McDowell JE, Brown GG, Paulus M, Martinez A, Stewart SE, Dubowitz DJ, Braff DL (2002) Neural correlates of refixation saccades and antisaccades in normal and schizophrenia subjects. Biol Psychiatry 5h:216-223

28. MeKenma P, Warrington $E$ (1983) The graded naming test. NFER-Nelson, Oxford

29. Mizuno M (1986) Neurotological findings in amyotrophic lateral sclerosis. Auris Nasus Larynx 13(SuppI 2):S139-S146

30. Mort DJ, Perry RJ, Mannan SK, Hodgson TL, Anderson E, Quest R, McRobbie D, McBride A, Husain M, Kennard C (2003) Differential cortical activation during voluntary and reflexive saccaces in man. Neuroimage 18:231-246

31. Muri RM, Heid O, Nirkko AC, Ozdoba C, Felblinger J, Schroth $G$, Hess CW (1998) Functional organisation of saccades and antisaccades in the frontal lobe in humans: a study with echo planar functional magnetic resonance imaging. I Neurol Neurosurg Psychiatry 65:374-377

32. Neary D, Snowden JS, Gustafson L, Passant U, Stuss D, Black S, Freedman M. Kertesz A, Robert PH. Albert M. Boone K. Mille BL, Cummings J, Benson DF (1998) Frontotemporal lobar degeneration: à consensus on clinical diagnostic criteria. Neurology 51:1546-1554

33. Nelson H, Willison I (1991) Restandardisation of the NART against the WAIS-R. NFER-Nelson, Windsor

34. Ohki M, Kanayama R, Nakamura T, Okuyama T, Kimura $Y$ Koike $Y$ (1994) Ocular abnomalities in amyotrophic lateral sclerosis. Acta Otolaryngol Suppl 511:138-142

35. Okuda B, Yamamoto T, Yamasaki M, Maya K, Imai T (1992) Motor neuron disease with slow eye movements and vertical gaze palsy. Acta Neurol Scand 85:71-76

36. Palmowski A, Jost WH, Osterhage I, Prudlo J, Kasmann B, Schimnigk K, Ruprecht KW (1995) Disorders of eye movement in anyotrophic Jateral sclerosis-report of 2 patients. Klin Monatsbl Augenheilkd 206:170-172

37. Palmowski A, Jost WH, Prudlo J, Osterhage J, Kasmann B Schimrigk K, Ruprecht KW (1995) Eye movement in amyotrophic lateral sclerosis: a longitudinal study. Ger J Ophthalmol 4:355-362

38. Pierrot-Deseilligny $\mathrm{CM}$, Muri RM, Ploner $\mathrm{CJ}$, Gaymard $\mathrm{B}$, Demeret S, Rivaud-Pechoux $S$ (2003) Decisional role of the dorsolateral prefrontal cortex in ocular motor behaviour. Brain 126:1460-1473

39. Pierot-Deseilligny $C R$, Rivand $S$, Gaymard B, Agid $Y(1991)$ Cortical control of reflexive visually guided saccades. Brain 114:1473-1485

40. Rivaud S, Muri RM, Gaymard B, Vermersch AI, Pierrot-Deseilligny $C$ (1994) Eye movement disorders after frontal eye field lesions in humans. Exp Brain Res 102:110-120

41. Saito S, Yamamoto H (1989) Analysis of oculomotor disorders in motor neuron disease. Rinsho Shinkeigaiu 29:969-975

42. Shaunak S, Orreil RW, O'Sullivan E, Hawken MB, Lane RJ, Henderson L, Kennard C (1995) Oculomotor function in amyotrophic lateral sclerosis: evidence for frontal impaiment. Ann Neurol 38:38-44

43. Tanaka M, Lisberger SG (2001) Regulation of the gain of visually guided smooth-pursuit eye movements by frontal cortex. Nature 409:191-194

44. Taraka M, Lisberger SG (2002) Enhancement of multiple components of pursuit eye movement by microstimulation in the arcuate frontal pursuit area in monkeys. J Neurophysiol 87:802818

45. Thier P, Ilg UJ (2005) The neural basis of smooth-pursuit eye movements. Curr Opin Neurobiol 15:645-652

46. Trenerry M, Crosson B, DeBoe I, Leber W (1989) STROOP Neuropsychological Screening Test Manual. Psychological Assessment Resources, Inc, Lutz

47. Ushio M, Iwasaki S, Sugasawa K, Murofushi T (2009) Atypical motor neuron disease with supranuclear vertical gaze palsy and slow saccades. Auris Nasus Larynx 36:85-87

48. Warrington EJ, James $M$ (1991) The visual object and space perception battery. Thames Valley Test Company, Bury $S$ Edmunds

49. Zigmond AS, Snaith RP (1983) The hospitai anxiety and depression scale. Acta Psychiatr Scand 67:361-370 